\title{
Inhaltsverzeichnis
}

\section{zu Band IV}

\section{Kommentar zur Grundbuchordnung}

Ergänzungen und Berichtigungen (ErgVerz) . . . . . . . . . . . . . . 3571 zu Band I

Abkürzungsverzeichnis usw. . . . . . . . . . . . . . . . . . . . 3571

Gesetzestexte $(G T)$. . . . . . . . . . . . . . . . . . . . . . . . . 3572

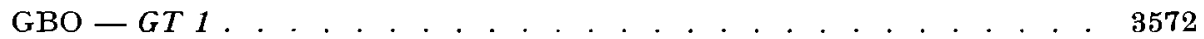

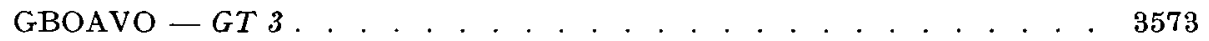

GBVfg $-G T 4 \ldots . . \quad . \quad . \quad . \quad . \quad . \quad . \quad . \quad . \quad . \quad . \quad . \quad . \quad 3573$

GBOGeschO - GT 15, 15a . . . . . . . . . . . . . . . . 3573

Ausfertigung der Hypothekenbriefe usw $-G T 16$. . . . . . . . . . . . 3592

Baden-Württemberg - GT $18 f f$. . . . . . . . . . . . . . . . . . . 3592

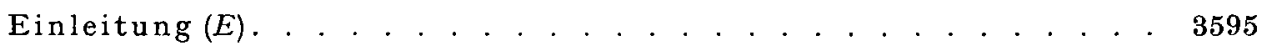

Grundbuchordnung ua $-\mathrm{E} 1 \mathrm{ff}$. . . . . . . . . . . . . . . . . . 3595

Ergänzungsrecht $-\mathbf{E} 25 \mathrm{ff}$. . . . . . . . . . . . . . . . . . . . . 3596

Kommentierung . . . . . . . . . . . . . . . . . . . . 3600

$\S 1$. . . . . . . . . . . . . . . . . . . . . . 3600

$\S 2$. . . . . . . . . . . . . . . . . . . . . . . . . . . . . . 3621

$\S 3$. . . . . . . . . . . . . . . . . . . . . . . . . 3631

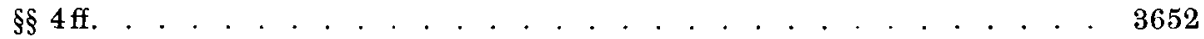

zu Band II

$\S 13$ Vorbem . . . . . . . . . . . . . . . . . . . . . . . . . . . 3661

$\S 13$. . . . . . . . . . . . . . . . . . . . . . . . 3682

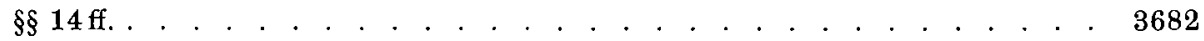

$\S 18$. . . . . . . . . . . . . . . . . . . . . . . . 3684

$\S 19$. . . . . . . . . . . . . . . . . . . . . . . . . . . . . . 3694

$\S 20$. . . . . . . . . . . . . . . . . . . . . . . . . . . . . . . 3698

$\S 22$. . . . . . . . . . . . . . . . . . . . . . . . . . . . . . 3723

$\S 23$. . . . . . . . . . . . . . . . . . . . . . . . . . . . . . . . 3726

$\S 25$. . . . . . . . . . . . . . . . . . . . . . . . . . 3727

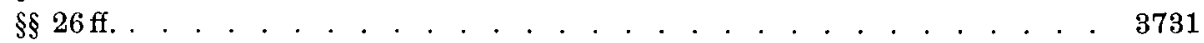

$\S 29$. . . . . . . . . . . . . . . . . . 3736

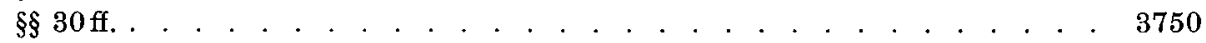

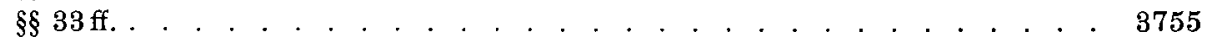

229 Meikel-Imhof-Riedel, GBO, Bd. IV III 
zu Band III

$\S 38$. . . . . . . . . . . . . . . . . . . . . . . . . . . . . . . 3769

$\S \S 39$ ff. . . . . . . . . . . . . . . . . . . . . . . . . . . . . . . 3772

$\S 45$. . . . . . . . . . . . . . . . . . . . . . . . . . . . . 3774

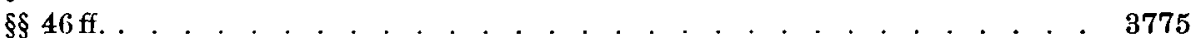

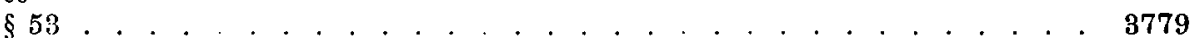

$\S 54$. . . . . . . . . . . . . . . . . . . . . . . . . . . . . . . 3781

$\S 55$. . . . . . . . . . . . . . . . . . . . . . . . . . . . . 3781

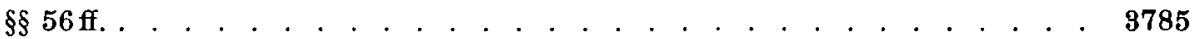

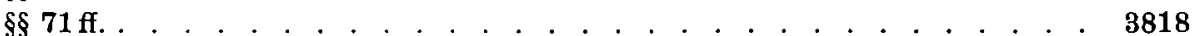

$\S \S 82 \mathrm{ff}$. . . . . . . . . . . . . . . . . . . . . . . . . . . . . . . 3823

$\S 116 \mathrm{ff}$. . . . . . . . . . . . . . . . . . . . . . . . . . . . . . 3823

Anhang

Loseblatt-Grundbuch - Anh 41 ff. . . . . . . . . . . . . . . . . . . 3831

Aktenordnung - Anh 56, 57, 57a . . . . . . . . . . . . . . . . . . 3836

FGG-Verfahren - Anh 58 . . . . . . . . . . . . . . . . . . . . . 3837

Kostenrecht - Anh 59. . . . . . . . . . . . . . . . . . . . . . . 3838

Notarrecht - Anh $60 \mathrm{ff}$. . . . . . . . . . . . . . . . . . . . . . . 3838

Beurkundungsgesetz - Anh 63 . . . . . . . . . . . . . . . . . . . 3866

Wohnungs- und Teileigentum grundbuchmäBige Behandlung — Anh $66 \quad$ 3867

Anerben- und Höferecht - Anh 85 ff. . . . . . . . . . . . . . . . . 3870

LandarbeiterVO - Anh 116 . . . . . . . . . . . . . . . . . . . . 3876

Lastenausgleichsgesetz - Anh 121 . . . . . . . . . . . . . . . . . 3876

Grunderwerbsteuergesetz - Anh 129, 135 . . . . . . . . . . . . . . 3877

Rechtspflegergesetz 1969/1970 - Anh 137 . . . . . . . . . . . . . . 3877

Grundbuch und Liegenschaftskataster — Anh $139 \mathrm{ff} . .$. . . . . . . . . 3879

Nachtrag $(N)$ Ergänzungen während des Drucks . . . . . , . . . . . 3898

Gesetzesregister (GesReg) . . . . . . . . . . . . . . . . . . . . . . . 3904

I. Hinweise auf abgedruckte gesetzliche Vorschriften . . . . . . . . . 3904

1. Bundesrecht, früheres Reichsrecht ua . . . . . . . . . . . . . 3904

2. Vorschriften des Bundesministers der Justiz und der Bundesbank . 3908

3. Landesrecht . . . . . . . . . . . . . . . . . . . . . 3908

4. AVRJM ua zum Grundbuchrecht . . . . . . . . . . . . . . . 3911

II. Hinweise auf wichtige besprochene grundbuchrechtliche Vorschriften . 3914

1. VO zur Ånderung des Verfahrens in GBSachen . . . . . . . . . 3914

2. Gesetz über Maßnahmen auf dem Gebiete des Grundbuchwesens . 3915

3. VO zur Ausführung der $\mathrm{GBO}$. . . . . . . . . . . . . . . . 3915

4. Grundbuchverfügung . . . . . . . . . . . . . . . . . . . 3916

5. Geschäftsordnung für die Grundbuchämter . . . . . . . . . . 3923

6. Ausfertigung der Hypothekenbriefe usw . . . . . . . . . . . . . 3926

7. Grundbuch und Kataster . . . . . . . . . . . . . . . . . . 3926

8. Grundbuch und Wohnungseigentum . . . . . . . . . . . . . 3927

9. Aktenordnung . . . . . . . . . . . . . . . . . . . . . . . 3929

10. FGG . . . . . . . . . . . . . . . . . . . . . . . . . 3929

11. Bundesnotarordnung . . . . . . . . . . . . . . . . . . 3931

12. Baden-Württemberg . . . . . . . . . . . . . . . . . . . . 3932

13. Bayern . . . . . . . . . . . . . . . . . . . . . . 3936

Sachregister . . . . . . . . . . . . . . . . . . . . . . . . . . $\mathbf{3 9 4 3}$ 
Ergänzungen und Berichtigungen (ErgVerz) 
